\title{
Predicting Catalytic Pyrolysis Aromatic Selectivity from Pyrolysis Vapor Composition using Mass Spectra Coupled with Statistical Analysis
}

\author{
Anne K. Starace*1, David D. Lee ${ }^{1}$, Kristen T. Hietalal, Yeonjoon Kim², Seonah Kim², Anne E. \\ Harman-Ware ${ }^{1}$ and Daniel L. Carpenter ${ }^{1}$ \\ ${ }^{1}$ National Renewable Energy Laboratory, 15013 Denver West Parkway, Golden, Colorado \\ 80401, USA \\ ${ }^{2}$ Colorado State University, Chemistry Department, 1301 Center Ave, Fort Collins, Colorado \\ 80523, USA
}

Email address: anne.starace@nrel.gov

Supporting Information Includes:

Total number of pages: 3

Total number of figures: 2

Total number of tables: 0 


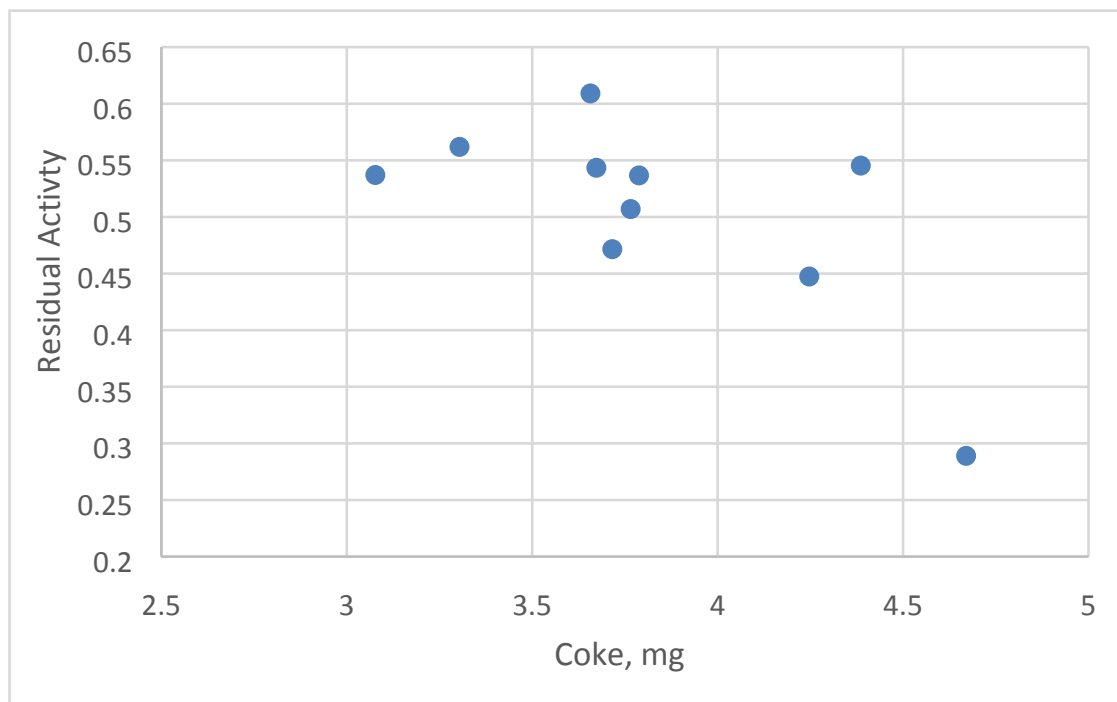

Figure SI-1: Milligrams of coke on catalyst vs. residual activity plotted for subset of feedstocks

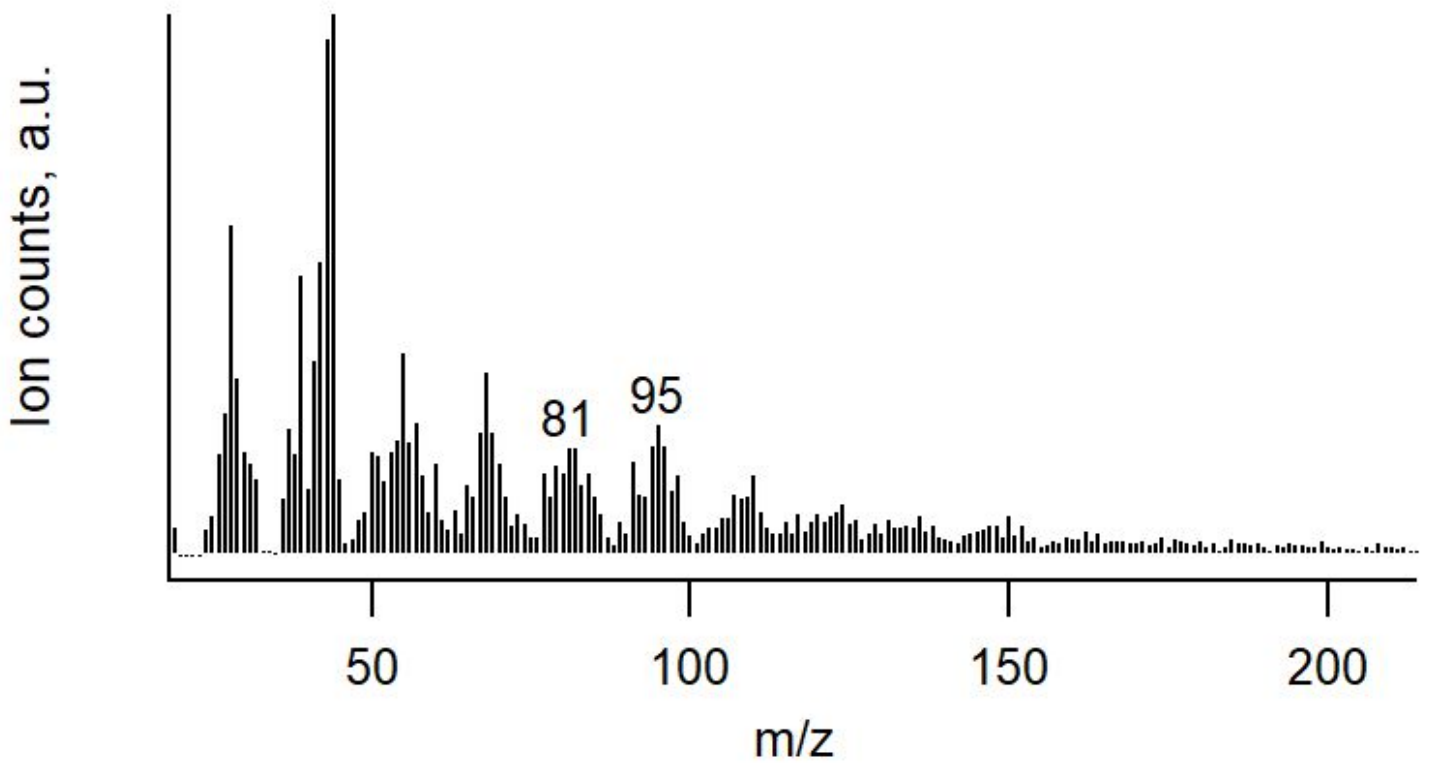

Figure SI-2: FP spectrum of grass clippings 
Lignin isolation method:

Loblolly pine was extracted with water and then ethanol for 48 hours, respectively, using a Soxhlet extractor. Air-dried extractives-free pine was ground at $4{ }^{\circ} \mathrm{C}$ for two weeks, in porcelain jars with zirconia media under a nitrogen atmosphere. Ball milled pine $(149 \mathrm{~g})$ was extracted with $0.5 \mathrm{~L}$ of $96 \%$ dioxane/H2O (v/v) for 2 days with vigorously stirring. The suspension was filtered and solid residue was extracted with the same solvent for additional 2 days. The extraction step was repeated two times, for a total of 6 days. The solvent in the combined filtrate was removed at $40^{\circ} \mathrm{C}$ under reduced pressure to get crude MWL. The crude MWL was dissolved in $20 \mathrm{ml}$ of $90 \%$ acetic acid and precipitated into 1.0L of deionized water. The precipitate was collected by centrifugation and then washed with water 4 times until acetic acid was removed. Freeze dried precipitate was dissolved in $20 \mathrm{ml}$ of 1,2-dichloroethane/ethanol $(2: 1, \mathrm{v} / \mathrm{v})$ and precipitating into diethyl ether $(150 \mathrm{ml})$. The precipitate was recovered by centrifugation and then washed with the ether 2 times. The precipitate was dried in a vacuumed desiccator for 2 days to obtain loblolly pine MWL (2.54g, $1.72 \mathrm{wt} \%)$ 